\title{
Mechanical colonic obstruction due to diaphragmatic hernia. Report of a case
}

\author{
Rodolfo Batista-Castillo, María José Cacheda-Madriñán, Helena Subirana \\ and María Clara López-Sanclemente
}

Department of General Surgery and Digestive Diseases. Hospital de Sant Joan Despí Moisès Broggi.

Consorci Sanitari Intregral. Barcelona, Spain

\section{INTRODUCTION}

Diaphragmatic hernias are defined as the passage of abdominal contents into chest cavity through a defect of the diaphragm. They may be congenital (Morgagni or Bochdalek) and acquired (traumatic). We describe a case of a patient with intestinal obstruction secondary to traumatic incarcerated diaphragmatic hernia, the diagnostic and therapeutic process.

\section{CASE REPORT}

A 31 year old man with medical history of sharp stab wound in left costal margin (mid-axillary line) about 15 years ago, requiring surgical treatment, without apparent sequelae. Came to the emergency with 24-hour of clinical evolution characterized by malaise, diffuse abdominal cramping pain, associated with nausea and vomiting. On physical examination, distension, bloating and defense, predominantly on the left side. No significant findings on blood tests. Abdominal radiograph showed dilated ascending and transverse colon with cecal diameter of 10-11 cm. Abdominal CT reporting presence of left diaphragmatic hernia containing transverse colon loop, conditioning occlusive state (Figs. 1 and 2). Emergency

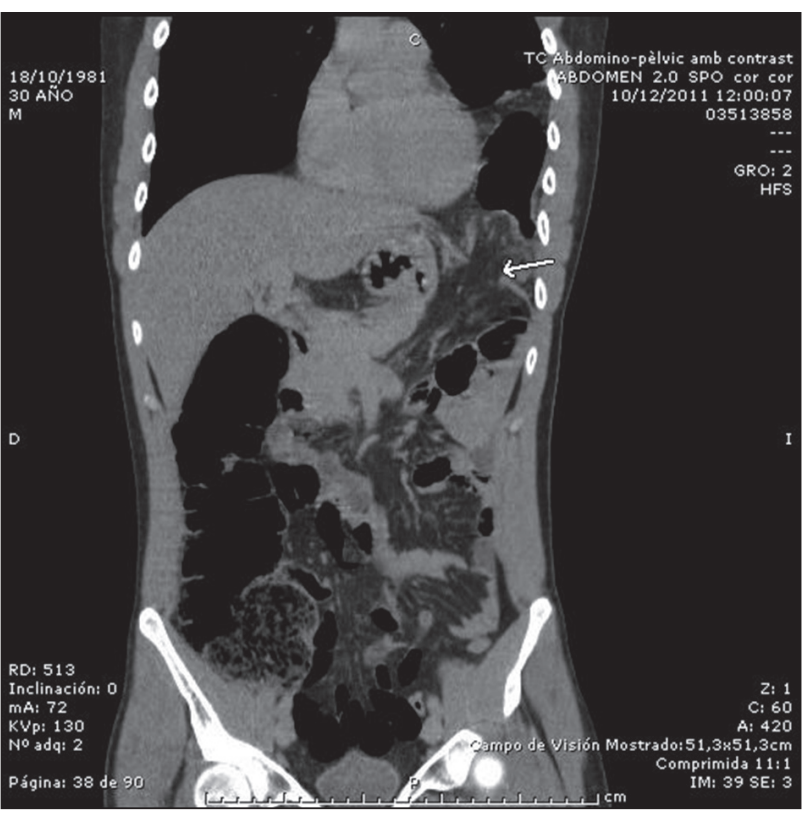

Fig. 1.

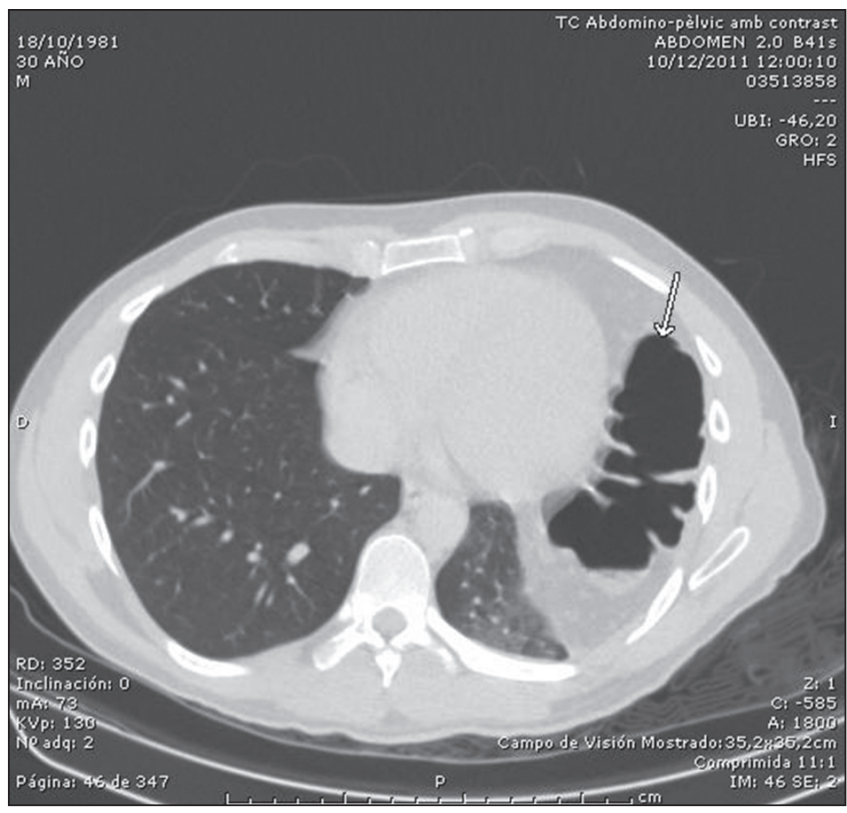

Fig. 2. 
surgery (exploratory laparotomy average) is decided, objectifying left diaphragmatic hernia orifice with $5 \mathrm{~cm}$ of diameter, containing transverse colon $(25 \mathrm{~cm})$ and perfused properly omentum; hernia content reduction is performed, respecting the pleura and repairing the defect. Uneventful postoperative.

\section{DISCUSSION}

Traumatic injuries of the diaphragm are the result of severe and often blunt trauma. Most of the cases are diagnosed late, leaving a latent diaphragmatic hernia, which may manifest with symptoms ranging from unspecific to strangulation of a loop of bowel. Specific signs of left diaphragmatic rupture are intrathoracic herniation of hollow viscera, abnormal location of the nasogastric tube above the diaphragm, confirming with oral contrast. CT scan should be performed. Requires urgent surgical treatment: Direct suture with non-absorbable material by laparotomy access.

\section{RECOMMENDED REFERENCES}

1. Figueroa Becerra JH, Gutiérrez Dávila AF, Salinas Soto J, Mendoza García JM, Monge Margali J. Presentación tardía de hernia diafragmática traumática con compromiso de colon. Rev Hosp Jua Mex 2007;74(1):35-9.

2. Menéndez Sánchez P, Villarejo Campos P, Padilla Valverde D, Sánchez García S, Jara Sánchez A. Obstrucción intestinal tardía como consecuencia de una hernia diafragmática postraumatismo. Cir Cir 2012;80:72-5.

3. Picetti E, Mergoni M. Traumatic diaphragmatic hernia. N Engl J Med 2011;365:14. 